\title{
THE MECHANISMS OF CORNEAL GRAFT FAILURE IN THE RAT
}

\author{
MUTSUO KATAMI \\ Kanagawa, Japan
}

\begin{abstract}
SUMMARY
The success rate of corneal transplantation is very similar to that of other organ transplantations because corneal transplants can induce an allograft rejection similar to other organ transplants. Only the centre of the cornea can be considered an immunologically privileged site. The reasons for this are considered in this review of experimental corneal grafting which has led to an understanding the immunological mechanisms behind corneal graft rejection. The topics discussed include the role of antigen presenting cells (APCs) in experimental corneal graft rejection and their distribution in the cornea.
\end{abstract}

Medawar ${ }^{1-3}$ reported the histocompatibility relationships between donor and recipient and the role of specific immunity in heterotopic skin graft rejection by using the anterior chamber of the eye. Medawar ${ }^{3}$ described on the basis of the immunised rabbit model that, 'a skin homograft survives transplantation to the eye of a specifically and strongly immunised rabbit if, and only if, it remained unvascularised. The experiments provide further evidence for the general rule that transplantation immunity is the outcome of a systemic and not a local reaction; and they offer a rational explanation for the well-known clinical success of corneal homografts in human beings.'

However, the clinical demonstrations by Maumenee $e^{4-6}$ that the corneal graft might be subject to immunological rejection, and that this process might account for a substantial proportion of those cases of late clouding of corneal allografts, prompted numerous investigators to investigate each of the factors which might account for immunological privilege where it exists and for specific graft rejection when it occurs.

Nowadays, recent improvements in microsurgery for orthotopic corneal transplantation in the rat (in

Correspondence to: $\mathrm{Dr}$ M. Katami, MD, PhD (Cantab), Department of Ophthalmology, School of Medicine, Kitasato University, 1-15-1 Kitasato, Kanagawa, Japan 228. which the major histocompatibility complex (MHC), including the associated immune response genes, of many strains is well defined in an inbred animal line ${ }^{7}$ ), have enabled some aspects to be studied in a more defined manner.

\section{EXPERIMENTAL CORNEAL TRANSPLANTATION}

Heterotopic Skin Graft in the Anterior Chamber of the Eye Using Sensitised Rabbit

In 1948, Medawar used heterotopic skin allografting as a means for studying the part played by blood and lymph vessels in transplantation immunity in particular regions of the body with major anatomical peculiarities. ${ }^{3}$ These regions were the brain, which lacked a lymphatic drainage system, and the anterior chamber of the eye, in which (whether vascularised or not) the epithelium of skin allografts showed the same migratory and mitotic activity as any other system. The experiment showed that a skin allograft $(1 \mathrm{~mm} \times 1 \mathrm{~mm})$ transplanted to the anterior chamber of the eye of a specifically immunised rabbit was destroyed if it was penetrated by blood vessels. On the basis of these experiments, Medawar summarised four possible reasons for the success of clinical corneal transplantation:

1. The dosage of foreign tissue involved in corneal allografting may be ineffectively small. ${ }^{1,8}$ There may indeed (though it has not been demonstrated) be a threshold of (antigen) dosage below which an allograft cannot immunise its recipient strongly enough to secure its own breakdown.

2. Because of the feebleness of immunisation, breakdown (if it occurs) may be delayed in onset and prolonged in execution.

3. Corneal allografts cannot elicit immunity, even if they could succumb to it.

4. Corneal allografts, being unvascularised, cannot succumb to an immune reaction even if they can initiate one. 
It is notable that the rejection of a skin allograft in the anterior chamber did not start in specifically immunised rabbits before the vascularisation between the tissue and the anterior segment of the eye was established. Medawar thought explanation (4) was singly sufficient and believed this conclusion offered a rational explanation for the clinical success of corneal transplantation.

\section{Heterotopic Skin Graft in a Pocket of Cornea Using Sensitised Rabbit}

Medawar's concept of grafting skin to regions of the body with major anatomical peculiarities was developed using a skin graft $(2 \mathrm{~mm} \times 3 \mathrm{~mm})$ inserted into a small pocket of the avascular cornea of a rabbit which had previously been heavily immunised by its donor's skin. ${ }^{9}$ The skin allograft was thus isolated from the aqueous humour or cells in the anterior chamber. Second-set skin grafts to the chest wall and into the avascular corneas were transplanted simultaneously. The skin grafts to the chest wall showed complete breakdown by day 7 at the latest, ${ }^{1}$ but the grafts into the cornea were still alive up to day 20 at which time all animals were killed. It was found that all the corneal grafts (except those that had been technically unsuccessful through exposure by perforation of the pocket and those that had become vascularised) were still alive when removed from the cornea at up to 20 days.

In contrast, corneal grafts (a split stroma about $0.1 \mathrm{~mm}$ in thickness, $3 \mathrm{~mm} \times 4 \mathrm{~mm}$ in size) implanted to the chest wall were not tolerated by the host and the effect on the host was to accelerate the destruction of further heterotopic corneal allografts later transplanted from the same donor. In other words, the corneal allografts, like skin allografts, had immunised their host. The conclusion from these experiments was that the cornea was not an 'immunologically privileged' tissue but a normal tissue in an immunologically privileged position.

Billingham and Boswell ${ }^{9}$ thought that tissue transplantation immunity was ineffective within the interlamellar cornea of the specifically immunised rabbit so long as it remained avascular. They thought that this concept of an 'immunologically privileged site' offered a sufficient biological explanation for the clinical success of corneal transplantation. At the very least, the interlamellar position of the cornea provided its immunological privilege by not allowing the efferent limb of graft rejection to operate efficiently in the sensitised rabbit model.

\section{Analyses of an 'Immunologically Privileged Site' in Sensitised Rabbit}

The rapid rejection of grafted tissue is usually attributed to incompatibility at the major histocompatibility complex (MHC). Allografts of both normal and malignant tissues have repeatedly been transplanted to anatomically unnatural sites for a variety of purposes. Orthotopic corneal transplantations have been used therapeutically with a high degree of success. Comparison of the fates of allografts transplanted to certain sites (including the anterior chamber of the eye, the cornea, the hamster's cheek pouch, the testis and the brain) with the fates of similar grafts transplanted elsewhere in the body has revealed that these sites are immunologically privileged since they can sustain graft survival for anomalously long periods. ${ }^{10,11}$

Analyses of these immunologically privileged sites (especially the hamster's cheek pouch) have shown that their unique properties turn upon the absence of an effective lymphatic drainage pathway. That is, there is a break in the afferent limb of the immunological reflex. The vulnerability of vascularised allografts in such sites to a state of specific sensitivity in the host, following active or adoptive immunisation, indicates the integrity of the efferent pathway of the immunological reflex. The success of vascularised allografts in privileged sites does not refute the concept of peripheral sensitisation since patent lymphatic vessels may be necessary to transmit peripherally primed lymphocytes to lymphoid organs.

There are also a few immunologically privileged tissues, notably cartilage and trophoblast, which behave as though they are incapable of eliciting an immune response in sites where allografts of other tissues undergo prompt rejection, and they may also be highly resistant to an extant state of specific sensitivity. The existence of privileged sites where there is normally a high rate of cell proliferation and yet a very low incidence of spontaneous tumours, as in the hamster's cheek pouch, may present a challenge to the immunological tumour surveillance theory. The cornea is also considered to be a privileged site in which the absence of an effective lymphatic drainage pathway also limits the afferent limb of sensitisation, so that the histocompatibility antigens of the donor cornea are not presented to the host immune system and subsequent active or adoptive immunisation cannot theoretically be achieved.

Billingham and Boswell concluded in their classical study described above that the absence of recipient vessels in the corneal graft constituted an absolute barrier to the rejection process in the sensitised host. ${ }^{9}$

However, irrespective of whether the avascularity of the cornea acts primarily to prevent initial sensitisation of the host or prevents rejection once sensitisation has occurred, cell-mediated immunity would be developed slowly and moderately. Also, because post-operative chemosis is transient and suture-induced microvascularisation is a late or 
temporary phenomenon in the recipient bed after corneal grafting, the afferent and efferent limbs between the corneal graft and the recipient immune system may be established slowly and incompletely. Thus, although interaction between the donor transplantation antigens and the recipient immune system via blood vessels occurs eventually in corneal allografts, induction of cell-mediated immunity may be induced slowly and may well be moderated.

\section{Orthotopic Corneal Graft Using Non-sensitised Rabbit}

Using the non-sensitised rabbit model, experimental orthotopic corneal transplants were performed by Silverstein and Khodadoust. ${ }^{12}$ They stated that 'With the elegant demonstrations by Medawar and Billingham et al. of histocompatibility relationships between donor and recipient and of the role of specific immunity in allograft rejection, the very success of most corneal grafts implies to many that keratoplasty must be totally exempt from histoincompatibility and other immunological considerations.' This conclusion was also supported by their experiments, in which they used the established techniques to study the rejection of full-thickness and lamellar corneal allografts in rabbits. ${ }^{13}$

When a large penetrating corneal graft $(8 \mathrm{~mm})$ was placed centrally and the sutures were removed at the earliest possible time (10 days after grafting), vessels were found occasionally to reach the margin of the graft, but when a small penetrating corneal graft $(5 \mathrm{~mm})$ was employed, vascularisation of the recipient bed was limited to 1-2 mm near the limbus. These vessels became ghost vessels visible only by slit lamp examination. After 12 weeks a rejection reaction was observed in 2 of the 20 rabbits $(10 \%)$. During the course of corneal allograft rejection, the pre-existing peripheral ghost vessels were seen to reopen and a few capillary loops extended through the host cornea to the margin of the graft. This graft was termed 'the avascular penetrating graft', that is, 'the small penetrating graft in the avascular bed'.

When the large graft $(8 \mathrm{~mm})$ was placed centrally, the sutures were left in place until 14-16 days after transplantation to encourage and ensure vascularisation of the penetrating graft. At the time of suture removal under these circumstances, vessels from the limbus had extended through the recipient corneal stroma and penetrated the peripheral 1-2 $\mathrm{mm}$ of the donor button. This graft was termed 'the vascularised penetrating graft', or more precisely, 'the large penetrating graft in the avascular bed with additional induction of vascularisation by delaying removal of sutures'. At the end of the period, an allograft rejection reaction was observed in 36 of 50 eyes $(72 \%)$. When Silverstein and Khodadoust compared 'the avascular penetrating graft' and 'the vascularised penetrating graft', they emphasised the significance of vascularisation in corneal allograft rejection, rather than the size of the donor corneal buttons.

When bilateral deep-lamellar corneal grafts $(8 \mathrm{~mm})$ were placed centrally upon the prepared recipient beds and sutured in place, the sutures were removed on day 7 after grafting, at which time a small brush of vessels extended only some $0.5 \mathrm{~mm}$ from the limbus into the recipient cornea. The minimal vascular growth which did occur, quickly retreated following suture removal. The grafts remained clear and uncomplicated for the 8 week period, and no sign of a rejection process involving either epithelium or stroma was observed in any of 30 eyes. This graft was termed 'the avascular lamellar graft', or more precisely, 'the bilateral lamellar graft on the avascular bed'.

When bilateral deep-lamellar corneal grafts $(8 \mathrm{~mm})$ were placed eccentrically on the superior region of 40 recipient corneas, the sutures were left in place until the tenth post-operative day. At the time of suture removal blood vessels had, with varying severity, invaded the recipient corneal stroma from the limbus and had penetrated 1-3 $\mathrm{mm}$ into the donor graft itself. This graft was termed 'the vascularised lamellar graft', or more precisely, 'the bilateral eccentric lamellar grafts on the avascular beds with additional induction of vascularisation by delaying removal of sutures'. After 12 weeks both epithelium and stroma had succumbed to the rejection reaction in both eyes of 6 rabbits and the epithelium alone was rejected in both eyes of 4 rabbits $(50 \%)$. While there was no instance of unilateral rejection of only one of the graft pairs in a given host, the onset of rejection of the two grafts was not always simultaneous. In half of the animals in which rejection occurred, the process appeared to start first in one eye, usually the more heavily vascularised of the two. The second corneal graft would become engaged in the rejection process from 1 to 4 days later.

Silverstein and Khodadoust described that all lamellar and most of the penetrating corneal allografts were spared from involvement in the rejection process so long as they remained avascular.

Even though using the non-sensitised rabbit model, it seems that this agrees with the classical concept of an 'immunologically privileged' site for clinical corneal transplantation as described by Medawar ${ }^{3}$ and supported by Billingham and Boswell. ${ }^{9}$ However, there are several fundamental differences (graft tissue, size of the graft, site for grafting, unilateral or bilateral grafting, induction of post-operative vascularisation in the recipient bed, immune status of the recipient) among these experiments which are summarised in Table I. 


\section{Orthotopic Penetrating Corneal Graft Using Non- sensitised Inbred Rat}

Williams and Coster, ${ }^{14}$ performing orthotopic corneal allografts in the non-sensitised inbred rat model, left approximately 10 individual sutures in position indefinitely, so that a degree of vascularisation of the graft occurred. Using this suture in orthotopic corneal grafts into an avascular bed, there was 'microvascularisation', in which small irregularly distributed superficial vessels converged on the suture sites.

A similar degree of microvascularisation to that which has been observed in rats also occurs in human corneal grafts. In clinical practice, the time of removal of sutures is dictated by the clinical appearance. In avascular corneas (keratoconus and dystrophies) wound healing is slow and regular, and where nylon sutures have been used at least 12 months may have to elapse to obtain adequate healing between the graft/host junction before they are removed. ${ }^{15}$ Although even minimum vascularisation may be sufficient to complete the afferent limb of sensitisation and reduce the immunological privilege normally attributed to the cornea, the application of local steroid eye drops at the onset of signs of rejection usually controls the rejection response. ${ }^{15}$ For these reasons, an avascular corneal bed is able to provide only limited immunological privilege after transplantation because of this postoperative microvascularisation. This suture-induced microvascularisation in the recipient bed may effectively eliminate the status of the classical 'privileged' site. As the appearances are very similar, it is probable that this technique of penetrating corneal grafting in rats is a close model of an uncomplicated graft in an avascular bed of the recipient's cornea in humans.

This rat corneal grafting technique has been modified here in studies described below by using a continuous interlocked chain suture (8 or 9 bites). The advantage of this modification is that it keeps an even tension around the graft and ensures minimum suture-induced microvascularisation in the recipient bed. On the basis of the distance from the graft junction to the limbus, and because of the strong convexity of the rat cornea, placing a $3 \mathrm{~mm}$ diameter button into a rat cornea of $7 \mathrm{~mm}$ is comparable to grafting a $7 \mathrm{~mm}$ (medium-sized) button into a human cornea of $11 \mathrm{~mm}$. Donors and recipients were always males and weighed between 200 and $400 \mathrm{~g}$. All rats were obtained from a single supplier (Harlan Olac, Bicester, Oxon, UK).

Antigen Presenting Cells in Rat Cornea. Rat cornea contains both class I and class II MHC antigens, as demonstrated by immunohistological staining of corneal sections with general and specific monoclonal antibodies (Mab). ${ }^{16,17}$

Cryostat sections of the normal skin of DA $\left(\mathrm{RT} 1^{\mathrm{a}}\right)$ inbred rats when stained with immunoperoxidase and Mab F17-23-2 (specific for RT1B ${ }^{\mathrm{a}}$ ) and OX-29 (specific for leucocyte-common antigen) showed expression of class II positive dendritic cells, the dendritic cells being found in the dermis and the Langerhans cells in the epidermis with spindly cytoplasmic processes. Cryostat sections of the normal heart of DA inbred rats showed strong expression of class II antigens in the muscles and vascular endothelium. Serial sections of the cornea were examined at a 400 -fold magnification using a $\times 10$ eyepiece and $\times 40$ objective lens. Central and limbal areas of cornea were assessed separately. An average of nine fields per cornea were counted on each slide using a graticuled eyepiece with a square grid. The mean number of dendritic cells counted per field in the centre $(0.3 \pm 0.5$ with $\mathrm{F} 17-23-2)$ was less than that in the periphery $(3.3 \pm 1.4$ with $\mathrm{F} 17-23-2)$. Cryostat sections of normal DA corneas showed that the dendritic cells were present in small numbers

Table I. The fundamental differences contained within the experimental concept of an 'immunologically privileged' site

\begin{tabular}{|c|c|c|c|c|c|c|c|}
\hline Source & Animal & Graft tissue & Graft size & Grafting site & $\begin{array}{l}\text { Bilateral or } \\
\text { unilateral } \\
\text { grafting }\end{array}$ & $\begin{array}{l}\text { Induction of post- } \\
\text { operative vascularisation } \\
\text { in the recipient bed }\end{array}$ & $\begin{array}{l}\text { Pre- } \\
\text { immunisation }\end{array}$ \\
\hline Medawar $^{3}$ & Rabbit & Skin graft & $1 \times 1 \mathrm{~mm}$ & $\begin{array}{l}\text { Anterior } \\
\text { chamber of the } \\
\text { eye }\end{array}$ & Unilateral & $\begin{array}{l}\text { Possibly when the graft } \\
\text { touched the recipient } \\
\text { cornea }\end{array}$ & $\begin{array}{l}\text { Done by skin } \\
\text { graft }\end{array}$ \\
\hline $\begin{array}{l}\text { Billingham and } \\
\text { Boswell }^{9}\end{array}$ & Rabbit & Skin graft & $3 \times 4 \mathrm{~mm}$ & $\begin{array}{l}\text { Interlamella of } \\
\text { the central } \\
\text { cornea }\end{array}$ & Unilateral & $\begin{array}{l}\text { Possibly by the open } \\
\text { incision of the recipient } \\
\text { cornea }\end{array}$ & $\begin{array}{l}\text { Done by skin } \\
\text { graft }\end{array}$ \\
\hline \multirow[t]{3}{*}{$\begin{array}{l}\text { Silverstein and } \\
\text { Khodadoust }^{12}\end{array}$} & Rabbit & $\begin{array}{l}\text { Full-thickness } \\
\text { corneal graft }\end{array}$ & $\begin{array}{l}5 \mathrm{~mm} \\
\text { diameter }\end{array}$ & $\begin{array}{l}\text { Penetrated } \\
\text { corneal bed }\end{array}$ & Unilateral & $\begin{array}{l}\text { Maintain an avascular } \\
\text { bed insofar as possible }\end{array}$ & No \\
\hline & Rabbit & $\begin{array}{l}\text { Full-thickness } \\
\text { corneal graft }\end{array}$ & $\begin{array}{l}8 \mathrm{~mm} \\
\text { diameter }\end{array}$ & $\begin{array}{l}\text { Penetrated } \\
\text { corneal bed }\end{array}$ & Unilateral & $\begin{array}{l}\text { Additional } \\
\text { vascularisation by } \\
\text { delaying removal of } \\
\text { suture }\end{array}$ & No \\
\hline & Rabbit & $\begin{array}{l}\text { Deep-lamellar } \\
\text { corneal graft }\end{array}$ & $\begin{array}{l}8 \mathrm{~mm} \\
\text { diameter }\end{array}$ & $\begin{array}{l}\text { Surface of } \\
\text { corneal bed }\end{array}$ & Bilateral & $\begin{array}{l}\text { Additional } \\
\text { vascularisation by } \\
\text { placing cornea } \\
\text { eccentrically }\end{array}$ & No \\
\hline $\begin{array}{l}\text { Williams and } \\
\text { Coster }\end{array}$ & Rat & $\begin{array}{l}\text { Full-thickness } \\
\text { corneal graft }\end{array}$ & $\begin{array}{l}3 \mathrm{~mm} \\
\text { diameter }\end{array}$ & $\begin{array}{l}\text { Penetrated } \\
\text { corneal bed }\end{array}$ & Unilateral & $\begin{array}{l}\text { Possibly by remaining } \\
\text { individual sutures }\end{array}$ & No \\
\hline
\end{tabular}


compared with those seen in DA skin. Cryostat sections of normal AO corneas showed a similar distribution pattern of class II MHC positive dendritic cells in the cornea with Mabs OX-3 (specific for $\mathrm{RT}^{\mathrm{u}}{ }^{\mathrm{u}}$ ) and OX-29 (specific for leucocyte-common antigen). No detectable class II MHC positive cells were found in the corneal epithelium or endothelium. The schematic distribution of antigen presenting cells in the DA cornea is shown in Fig. 1.

Immunogenicity of Rat Cornea. It was discovered early by us ${ }^{18}$ that contrary to the concept of immunological privilege, a $3 \mathrm{~mm}$ orthotopic penetrating corneal graft between genetically different rat strains might be rejected even when transplanted into an avascular bed. That such rejection was under the control of basic transplantation antigens was established as follows. Isografts between DA rats survived indefinitely, fully allogeneic corneal grafts from DA to AO were found to be rejected rapidly in all instances even in an avascular bed (median survival time 11 days), corneas grafted from parent to $F_{1}$ were accepted indefinitely, whereas grafts from $\mathrm{F}_{1}$ to the parent were rejected (22 days), probably reflecting the reduced antigenicity of the $F_{1}$ donors. This is similar to the rejection time seen for other grafts placed in the strain combination of DA to AO. Orthotopic skin grafts were rejected at 9 days, heterotopic heart grafts were rejected at 6 days and orthotopic liver grafts were rejected at 17 days in the same strain combination. ${ }^{18,19}$ Histological sections of rejected corneas stained by haematoxylin and eosin showed a moderate mononuclear cell infiltrate in the stroma, a thin epithelium and often an absence or distortion of the endothelium with marked mononuclear cell infiltrate. ${ }^{18,19}$ By the use of the rejector combination of DA to AO, this experiment demonstrates that corneal graft rejection in an avascular bed obeys the basic laws of transplantation, in that

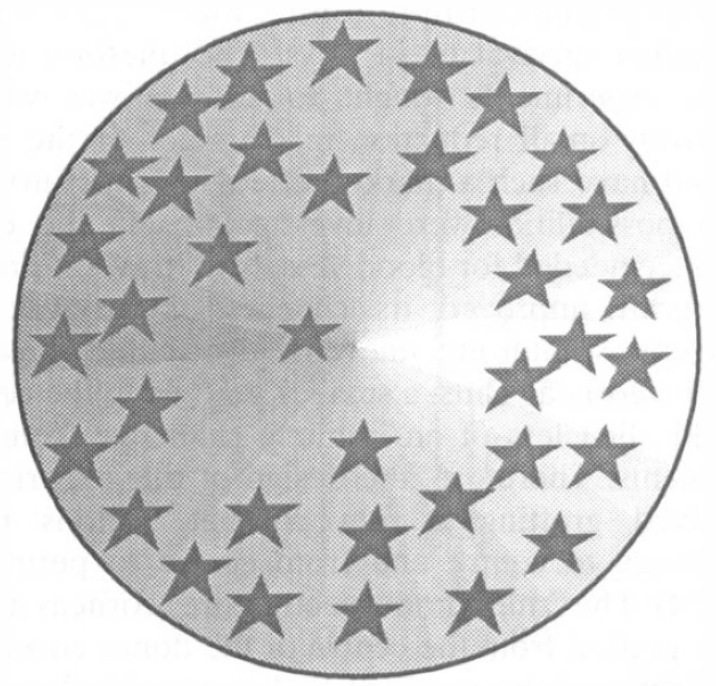

Fig. 1. Distribution of antigen presenting cells (shown as stars) in the DA cornea. grafts between genetically identical animals are accepted whereas grafts between genetically nonidentical animals are rejected with a speed which is dependent on genetic differences between donor and recipient. It should be noted that corneal allografts can undergo acute rejection even when transplanted into avascular beds and that antigenic disparity between donor and recipient is an important factor in corneal allograft rejection. Although only a small number of class II positive dendritic cells are present in a normal cornea, they may represent the most important stimulus to induce allogeneic reaction in corneal graft rejection.

\section{ROLE OF ANTIGEN PRESENTING CELLS (APCS) IN CORNEAL GRAFT REJECTION}

\section{Antigen Presentation}

In clinical organ transplantation, the demand in recent years has been for the development of more powerful and more specific immunosuppressive agents effective in lower dosages. In addition, there has been a shift away from the notion that the only way to prevent rejection in organ allografting is by systemic immunosuppression of the recipient. In some experimental situations it has been possible to achieve prolonged allograft survival without the need for intensive systemic immunosuppression. Some of the better known of these experiments include:

1. Neonatal tolerance in mice..$^{20}$

2. Tolerance induced by orthotopic liver allografts. $^{21,22}$

3. Organ culture preservation for mouse thyroid allografts $^{23}$ and rat pancreatic islet allografts. ${ }^{24,25}$

4. Retransplantation from long-surviving, passively enhanced $F_{1}$ rat renal allografts originally transplanted to parental recipients into the normal second parental recipients. ${ }^{26}$

5. UV-B irradiated donor-specific transfusions (DST) for rat pancreatic islet allografts. ${ }^{27}$

6. Site-specific immunosuppression for rat heart allografts ${ }^{28}$ rat kidney allografts ${ }^{29}$ and rabbit corneal allografts. ${ }^{30}$

The classical view of rejection is derived from the demonstration by Medawar that rejection is an immune process. ${ }^{1}$ His studies showed graft rejection

Table II. Dual antigen presentation theory

\begin{tabular}{ll}
\hline Route 1. & $\begin{array}{l}\text { Direct antigen presentation } \\
\text { Dendritic cells present in graft tissue directly } \\
\text { activate the recipient's T helper cells }\end{array}$ \\
Route 2. & $\begin{array}{l}\text { Indirect antigen presentation } \\
\text { MHC alloantigen of the graft is processed and } \\
\text { presented by the recipient's own dendritic cells }\end{array}$
\end{tabular}

MHC incompatible graft $=$ Route $1+$ route 2 (acute rejection) Non-MHC incompatible graft $=$ Route 2 (chronic rejection)

From Lechler and Batchelor. ${ }^{26}$ 
to have the properties of both specificity and memory which are characteristic of an immune response. With the demonstration that donor-specific tolerance could be induced in the newborn ${ }^{20}$ came confirmation of Burnet and Fenner's theoretical prediction concerning self versus non-self. ${ }^{31}$ The idea that rejection could be overcome became established through the understanding that it was mediated by the recognition of and response to genetically defined transplantation antigens. ${ }^{20}$

Although the evidence that graft rejection is an immune process is overwhelming, there is a problem in the theoretical explanation as to how it is brought about. The problem is most clearly expressed as the 'transplantation paradox'. ${ }^{32}$ This paradox is:

1. Graft rejection is an immune process initiated by recognition of and response primarily to MHC transplantation antigens.

2 The immune response to MHC antigens is the most violent primary immune reaction yet observed against any antigens.

3. The transplantation antigens as isolated molecules, whether they be class I or class II MHC antigens, are very weak immunogens.

The solution to the paradox comes from an understanding of antigen presentation and its role in immune induction. The theory of allogeneic reactivity is derived from the concept that two signals are required for $\mathrm{T}$ cell activation. The theory sees MHC antigen as the presentation control molecule of the immune system which by its very nature must be the component responsible for the restriction of $\mathrm{T}$ cell specificity (MHC restriction). The theory also postulates that two distinct classes of transplantation antigens exist: major and minor histocompatibility antigens. MHC antigens are cell surface structures which act as presentation control molecules. Non-MHC (minor) antigens are other cell surface components that do not express such a function, but can induce weak allograft rejection. The theory predicts that MHC antigen of itself is not the barrier to tissue grafting and that such a violent immune response against graft acceptance is provided by the function of APCs. There are two distinct roles for APCs in inducing graft rejection: direct and indirect antigen presentation. Direct antigen presentation is provided by APCs of the donor transplanted with the graft, whereas indirect presentation is provided by APCs in the recipient processing graft antigens. ${ }^{26}$ Acute allograft rejection is induced by the function of direct antigen presentation by donor APCs. For this reason, it is at least theoretically possible to reduce the ferocity of allograft rejection by removal of 'APCs' from donor tissue prior to grafting.

The APC-depleted graft thus obtains an antigeni- cally privileged status with regard to acute graft rejection. That is, it contains antigen expressed in a form that does not elicit an allograft reaction directly. However, graft rejection of such a graft can still take place via the normal immune mechanisms involving donor transplantation antigens processed by recipient APCs (indirect antigen presentation), and this may result in chronic rejection.

This section describes experiments designed to investigate the role of APCs present in the cornea on graft surival. Three different factors were studied in relation to the density of APCs: (1) size of corneal button, (2) position of the corneal button in the recipient bed, (3) immunomodulation of APCs by ultraviolet-B (UV-B) irradiation to donor corneas.

The Size of Corneal Button. The size of the donor corneal button was shown to be of critical importance for the fate of corneal grafts as follows. Four millimetre and $3 \mathrm{~mm}$ (standard size) diameter corneas grafted in avascular beds underwent acute rejection (10.5 days and 11 days respectively), whereas $2 \mathrm{~mm}$ and $1.5 \mathrm{~mm}$ corneas did not undergo acute rejection and survived for over 100 days (Figs. 2 and 3, Table III). Data suggested that the smaller the size of the donor cornea, the less was the corneal graft rejection. The 'privilege' in corneal allografting may result not just from the poor degree of vascularity in the recipient bed but also in the unique distribution of APCs in this particular tissue. The Position of the Corneal Button in the Recipient Bed. In these experiments, full-thickness corneas were grafted orthotopically and unilaterally into an avascular penetrating recipient bed, in order to investigate the contribution to the grafting site of the recipient bed. Using a $2 \mathrm{~mm}$ trephine, corneas grafted from the centre of the donor cornea to the centre of the recipient bed survived indefinitely ( $>100$ days). It must be remembered that this is in contrast to the results achieved with $3 \mathrm{~mm}$ corneal buttons placed centre-to-centre, which rejected with a median survival of 11 days. The question which these experiments sought to address was why a relatively small reduction in diameter of the graft should have such a marked effect on graft survival. Two possibilities were investigated: (1) the extra distance needed for blood vessels to 'travel' to reach the graft improved its chances of survival; (2) antigenic stimuli are unevenly distributed throughout the cornea. Thus, a smaller graft from the centre would elicit less of an immune challenge from the recipients. Therefore, the design of this experiment involved grafting $2 \mathrm{~mm}$ corneal buttons from periphery to centre and from centre to periphery (Fig. 4). The $2 \mathrm{~mm}$ (non-rejecting size) corneas which were grafted from the centre of the donor cornea to the centre of the recipient bed survived indefinitely ( $>100$ days). Ten corneas grafted from the centre to 


\section{Donor \\ Recipient Size of cornea}

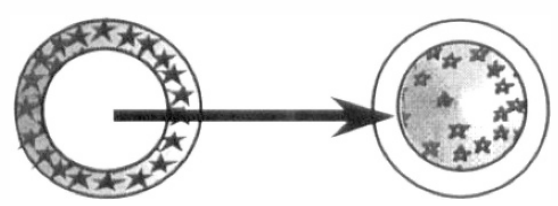

$4 \mathrm{~mm}$

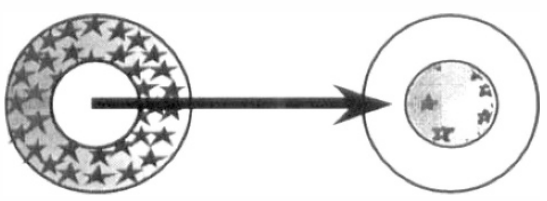

$3 \mathrm{~mm}$

(normal size)

$2 \mathrm{~mm}$
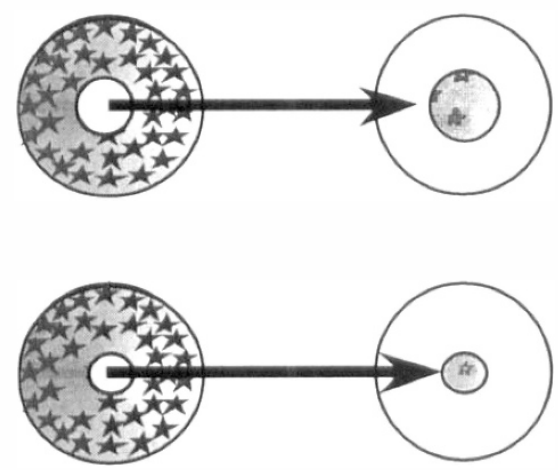

$1.5 \mathrm{~mm}$

Fig. 2. Different sizes of corneal allografts.

the periphery showed transient rejection in all instances, and 7 corneas were rejected chronically (96 days). In contrast, 4 of 10 corneas grafted from the periphery to the centre showed acute rejection, 1 cornea was rejected chronically, and the others survived indefinitely (99 days) as shown in Fig. 5 and Table IV.

The results achieved show quite clearly that a corneal button taken from the periphery of the cornea and placed in the centre will elicit acute graft rejection, with $40 \%$ of grafts failing in the first 20
Table III. The influence of size of the donor corneal button in orthotopic corneal grafts on avascular beds in the rat strain combination DA to AO

\begin{tabular}{llcc}
\hline $\begin{array}{l}\text { Diameter } \\
\text { of corneal } \\
\text { graft }(\mathrm{mm})\end{array}$ & Corneal graft survival (days) & $\begin{array}{c}\text { MST } \pm \text { SD } \\
(\text { days })\end{array}$ & $\begin{array}{c}\text { Median } \\
(\text { days })\end{array}$ \\
\hline 4 & $8,8,10,10,10,11,11,11$, & $10.4 \pm 1.6$ & 10.5 \\
3 & $12,13,10,11,11,11,11,11$, & $12.1 \pm 2.3$ & 11 \\
& $10,10,10,14,14,15,18$, & & \\
2 & $11,11,14,14,100$ & $92.6 \pm 23.4$ & $>100$ \\
1.5 & $26,{ }^{\mathrm{a}}(34) 100,100,(\times 8)$, & $95.6 \pm 13.9$ & $>100$ \\
\hline
\end{tabular}

MST, mean survival time.

${ }^{a}$ These grafts had minor rejections as they showed a transient rejection episode after operation, the end point of which is shown in parentheses, but subsequently they cleared and remained transparent until after the 100 day period of the experiments.

days. Such a result is compatible with a high density of donor APCs being grafted with such a button. In contrast, corneal buttons taken from the centre and placed at the periphery demonstrated no acute rejection, but instead showed chronic rejection. This is consistent with the involvement of recipient APCs, in high concentration at the periphery of the cornea, being involved in inducing this rejection. Such conclusions are entirely consistent with the clinical study on the involvement of APCs in the rejection of human corneas.

One possible explanation for the different patterns of corneal allografts in these experiments is that the density of dendritic cells is lowest in the central area but higher in the peripheral area. This unique distribution of dendritic cells in the cornea may also explain why a $2 \mathrm{~mm}$ fully allogeneic corneal graft from centre to centre does not elicit sufficient response to induce rejection ( $>100$ days), compared with a $3 \mathrm{~mm}$ corneal graft (11 days). The higher distribution in the peripheral area of the recipient bed may explain why a corneal graft from centre to periphery induces chronic rejection. In this situation,

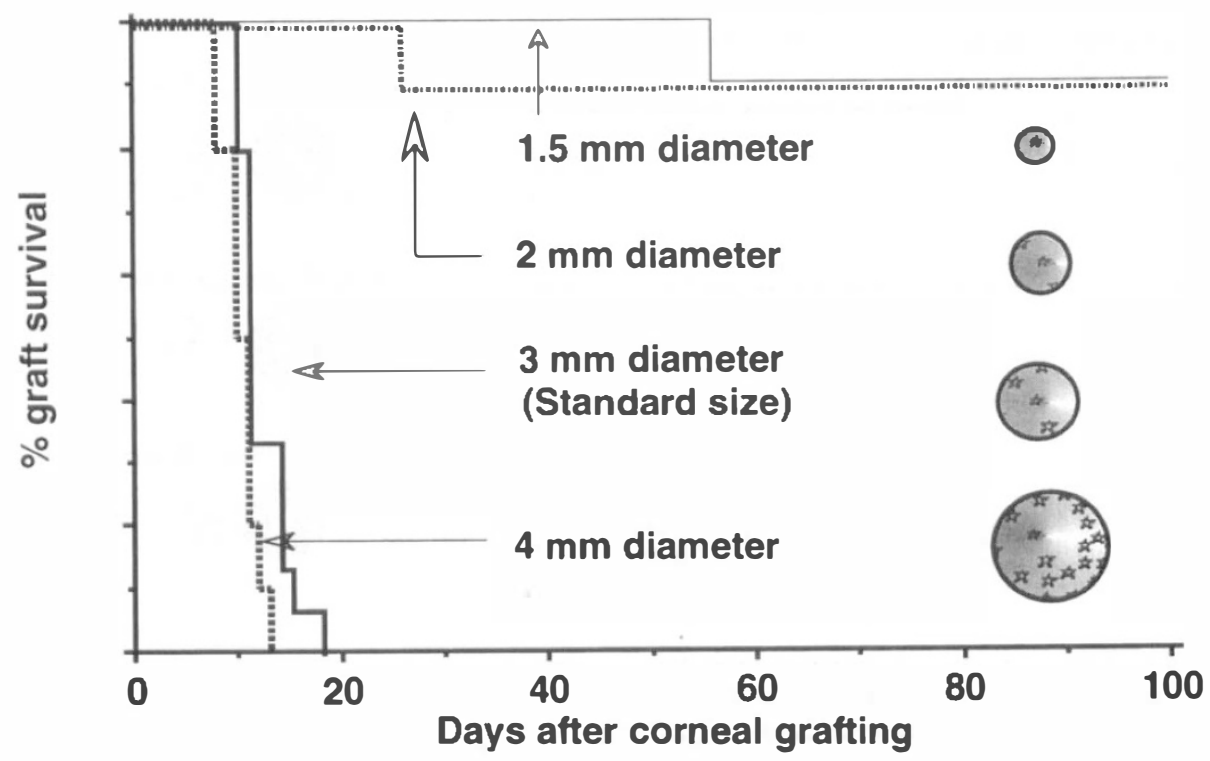

Fig. 3. Influence on graft survival of the size of the donor corneal button. 
Centre to Centre

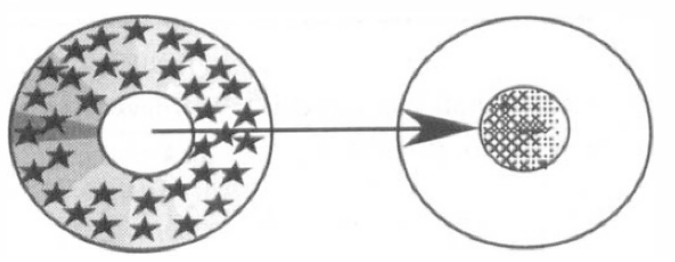

$2 \mathrm{~mm}$ non-rejecting size

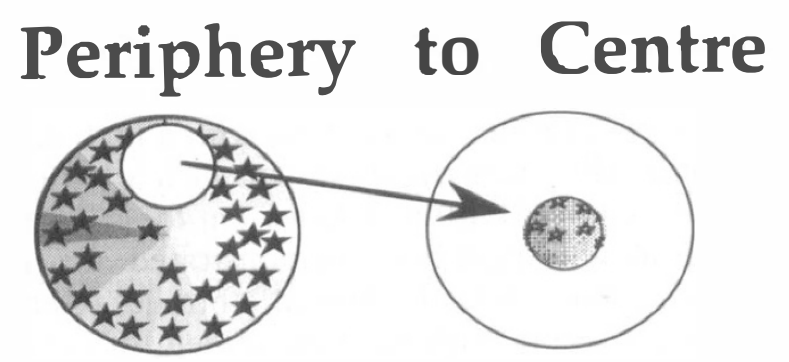

Centre to Periphery

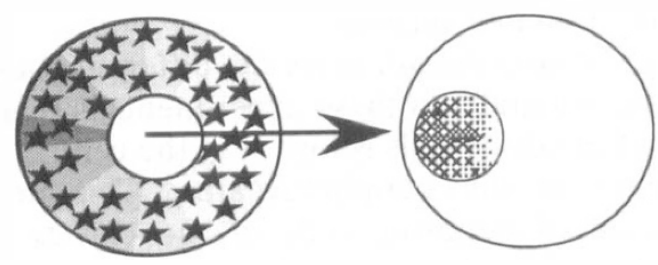

Fig. 4. Influence of the site of the cornea.

the graft can increase the indirect antigen presentation in allograft rejection. In contrast, the higher distribution in the peripheral area of the donor corneal button may explain why a corneal graft from periphery to centre induces acute rejection because
Table IV. The relative contribution of the site of the donor cornea and the recipient bed on corneal graft rejection in the AO avascular beds using $2 \mathrm{~mm}$ (rejecting size) DA corneal grafts

\begin{tabular}{|c|c|c|c|c|}
\hline $\begin{array}{l}\text { Site of } \\
\text { donor } \\
\text { cornea }\end{array}$ & $\begin{array}{l}\text { Site of } \\
\text { recipient } \\
\text { cornea }\end{array}$ & $\begin{array}{l}\text { Corneal graft } \\
\text { survival (days) }\end{array}$ & $\underset{\text { (days) }}{\mathrm{MST} \pm \mathrm{SD}}$ & $\begin{array}{c}\text { Median } \\
\text { (days) }\end{array}$ \\
\hline Centre & Centre & $\begin{array}{l}26^{\mathrm{a}}(34) 100,100 \\
100,100,100,100 \\
100,100,100\end{array}$ & $92.6 \pm 23.4$ & $>100$ \\
\hline Centre & Periphery & $\begin{array}{l}\text { (13) } 77,(14) 77, \\
\text { (10) } 86,(15), 87, \\
\text { (15) } 96,(15) 96, \\
\text { (11) } 98,(10) 100, \\
\text { (15) } 100,(24) 100\end{array}$ & $91.7 \pm 9.3$ & 96 \\
\hline Periphery & Centre & $\begin{array}{l}10,11,11,13, \\
(21) 98,(12) 100, \\
100,100,100, \\
100,\end{array}$ & $64.3 \pm 45.7$ & 99 \\
\hline
\end{tabular}

MST, mean survival time.

${ }^{a}$ These grafts had minor rejections as they showed a transient rejection episode after operation, the end point of which is shown in parentheses, but subsequently they cleared and remained transparent until after the 100 day period of the experiments.

the graft can increase the direct antigen presentation. Thus, a large corneal button carries with it more donor APCs and hence greater risk of acute rejection. A smaller button with fewer APCs has a greater chance of survival. This means that it is important for successful corneal grafting to use central regions of both donor and recipient corneas in order to minimise its antigenic load.

As described in previous papers, ${ }^{18,33}$ despite using fully allogeneic inbred rat strain combinations, there are different responder states (high, mild, low) for the fate of corneal grafts on avascular beds. Furthermore, there is not always an apparent correlation of the MHC-linked immune response (Ir) gene allele with the responder status of orthotopic corneal grafts. The apparently reduced importance of antigenic incompatibilities of MHC in

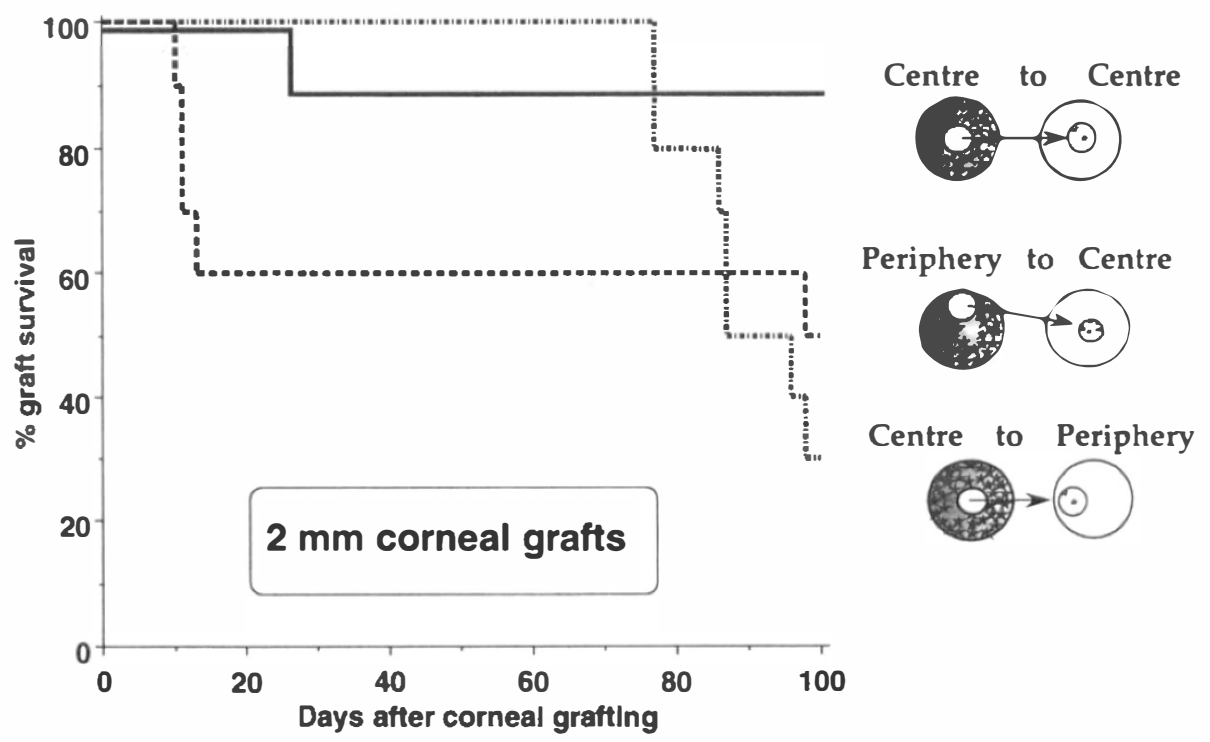

Fig. 5. Influence on graft survival of the site of donor cornea and recipient bed. 

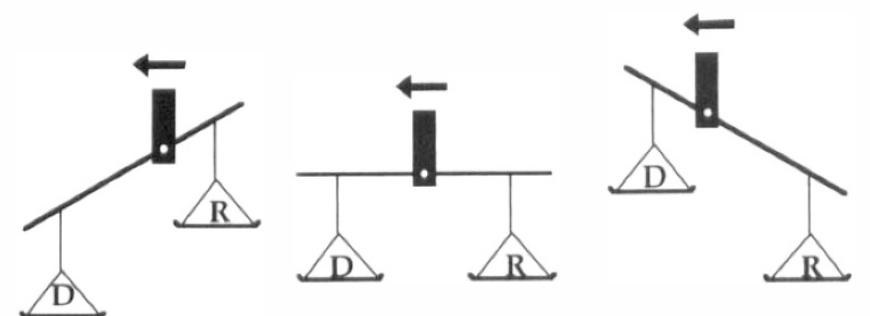

Fig. 6. Immunomodulation. D, donor antigen presenting cell; $R$, recipient $A P C$.

corneal graft rejection seems to be an outlaw of transplantation immunology.

However, using DA inbred rats and PVG congenic rats (mild responder status combination), the single incompatibility in either MHC or non-MHC antigens is not the main barrier to corneal transplantation. In particular, class II MHC incompatibility in isolation did not show any influence in corneal graft rejection. Interestingly, multiple incompatibilities in $\mathrm{MHC}$ and/ or non-MHC antigens can induce allograft rejection in various ways. ${ }^{36}$ Thus, the violent immune response against graft acceptance seems to be an allogeneic reaction provided through the function of APCs.

Corneal transplants were considered to be 'immunologically silent', rather than placed in an 'immunologically privileged' environment. It seems that this immunoreactive inferiority in corneal transplants may be a general phenomenon which is related to the relative lack of class II positive dendritic cells and their unique distribution in both donor and recipient cornea, or perhaps the relative functional imperfection of antigen presentation in the cornea. It has been reported that the magnitude of a $\mathrm{T}$ cell response can be a function of the concentration of antigen and the density of MHC class II antigens on an APC. ${ }^{34}$ The different survival times among the tissue and organ grafts with the 'pure' incompatibility of class II MHC antigens may be explained by the different density of MHC class II antigens.

It is possible to reduce the severity of allograft rejection by removal of APCs from donor tissue prior to transplantation. The APC-depleted graft thus obtains an antigenically privileged status with regard to acute graft rejection. As shown in Fig. 6, by shifting a fulcrum from right to left, it means that the function of donor APCs becomes less important than that of recipient APCs and also MHC incompatibility becomes less important than non-MHC incompatibility in graft rejection. In this situation, graft rejection becomes moderate and MHC matching becomes less important than non-MHC matching in tissue typing. This change of antigen presentation function in graft rejection can be quite beneficial to clinical tissue and organ transplantations (immunomodulation).
The Immunomodulation of APCs by Pretreatment with Ultraviolet- $B(U V-B)$ Irradiation. One of the first attempts at decreasing the effect of sensitisation on preoperative donor-specific transfusions (DST) in transplantation was with UV-B irradiation. ${ }^{27} \mathrm{UV}$ irradiated blood given 3 weeks, 2 weeks and 1 week prior to transplantation significantly prolonged the survival of pancreatic islet allografts in the combination LEW $\left(\mathrm{RT} 1^{1}\right)$ to $\mathrm{ACI}\left(\mathrm{RT} 1^{1 \mathrm{a}}\right)$ when compared with DST without UV-B irradiation. It was reported that rejection of mouse heterotopic corneal grafts was reduced by pretreatment with UVB-irradiation to the epithelial side of the donor eyes. ${ }^{35}$ In these experiments, an attempt has been made to remove APCs in the cornea using UV-B irradiation prior to transplantation.

Enucleated DA donor eyes were divided into two groups. For the epithelial surface irradiation the whole eye was placed, optic nerve side down, on moist gauze in a glass chamber. For endothelial surface irradiation, $3 \mathrm{~mm}$ donor corneal buttons were removed, turned upside down and put back in their original place on the donor corneas (Fig. 7). The whole eye was then placed in another glass chamber, optic nerve side down. Both chambers (without lids) were exposed to UV-B light sources (6 TL-40W/12 fluorescent lamps, Philips Light, Croydon, UK) at a distance of $20 \mathrm{~cm}$ from the source for 2.63 minutes (total irradiation $0.2 \mathrm{~J} / \mathrm{cm}^{2}$ ). The corneas were grafted into non-irradiated recipient beds of $\mathrm{AO}$ rats. Donor corneal buttons treated before grafting with UV-B irradiation either from the epithelium of the endothelium side showed a significant prolongation of corneal graft survival (>700 days; Fig. 8, Table IV). Histological examination of the grafts from DA corneas which were accepted and had already been UV-B irradiated prior to grafting showed very few DA class II positive dendritic cells, but a few AO class II positive dendritic cells were observed in the corneas.

Site-Specific Immunosuppression by the Use of Locally Applied Steroid Eye Drops. Local administration of steroid eye drops is universally used for the prevention of clinical corneal graft rejection. However, it is a less effective method of treatment against primary corneal graft rejection. This is also the situation in the experimental animal model. Orthotopic corneal grafts were performed using DA corneas in AO recipient rats $(n=10)$. One drop of $0.25 \% \mathrm{w} / \mathrm{v}$ steroid eye drops (prednisolone) was applied to the operated eyes (twice a day for 4 weeks), from day 0 to day 27 . Using this schedule, one graft was rejected at day 29 , and 9 of 10 corneal grafts survived beyond 100 days but were then chronically rejected (122.5 days; Fig. 7, Table V). Thus, the use of local steroid produced a significant improvement in corneal graft survival when 

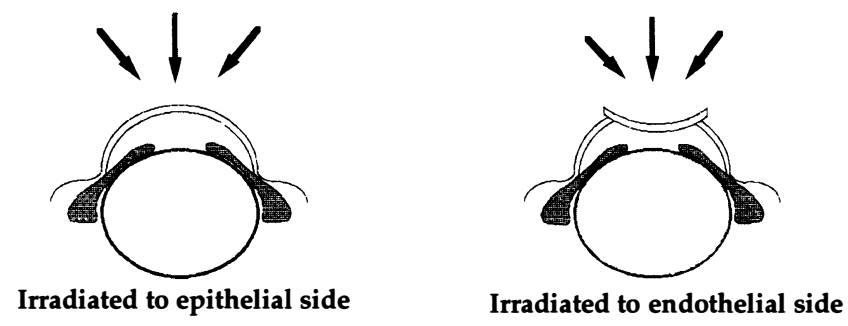

Fig. 7. UV-B irradiation to donor corneal buttons.

compared with the control group without immunosuppression (11 days). ${ }^{36}$

\section{CONCLUSION}

Medawar summarised four possible reasons for the success of clinical corneal transplantation. He suggested that the reason for corneal transplantation success was that 'corneal allografts cannot elicit immunity even if they could succumb to it' (3). This can be shown not to be the case. He also suggested that 'corneal allografts, being unvascularised, cannot succumb to an immune reaction even if they initiate one' (4). This too can be shown not to be the situation. His explanations (1) and (2), which relate to the inferiority of immune stimulus of corneal transplants, clearly indicate the concept of antigen presenting cells (APCs). This was a return to the APC concept, ${ }^{37}$ in that 'passenger leucocytes' carried in the donor tissue provide the major immunogenic stimulus for the host. ${ }^{38}$ Despite using an inadequate model for the concept of APCs, Medawar's profound insight into the mechanisms of corneal graft rejection has indeed proved to be correct.

Using a rat rejector strain combination (DA to $\mathrm{AO})$, experiments were undertaken to show the
Table V. Corneal graft survival treated with steroid eye drops or ultraviolet-B (UV-B) irradiation $\left(0.2 \mathrm{~J} / \mathrm{cm}^{2}\right)$ to the donor avascular corneal buttons and the recipient avascular corneal beds in orthotopic corneal grafts in the rat strain combination DA to $\mathrm{AO}$

\begin{tabular}{|c|c|c|c|}
\hline Group & $\begin{array}{l}\text { Corneal graft } \\
\text { survival (days) }\end{array}$ & $\begin{array}{l}\text { MST } \pm \text { SD } \\
\text { (days) }\end{array}$ & $\begin{array}{c}\text { Median } \\
\text { (days) }\end{array}$ \\
\hline Control (no steroid) & $\begin{array}{l}10(\times 3), 11 \\
(\times 7), 14(\times 3), \\
15,18\end{array}$ & $12.1 \pm 2.3$ & 11 \\
\hline $\begin{array}{l}0.25 \% \text { steroid eye } \\
\text { drops (twice/day, } 4 \\
\text { weeks) }\end{array}$ & $\begin{array}{l}29,104,106,122, \\
131,134,136, \\
141,160,162\end{array}$ & $122.5 \pm 38.1$ & 132.5 \\
\hline $\begin{array}{l}\text { Epithelial side of the } \\
\text { donor corneas }\end{array}$ & $\begin{array}{l}\mathrm{a}(19) 700,(22) \\
700,700(\times 8)\end{array}$ & $>700$ & $>700$ \\
\hline $\begin{array}{l}\text { Endothelial side of } \\
\text { the recipient corneas }\end{array}$ & $\begin{array}{l}(13) 700,(22) \\
700,700(\times 8)\end{array}$ & $>700$ & $>700$ \\
\hline
\end{tabular}

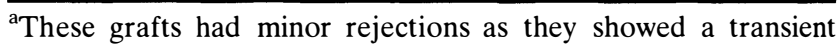
rejection episode after operation, the end point of which is shown in parentheses, but subsequently they cleared and remained transparent until after the 100 day period of the experiments.

importance of APCs in corneal graft rejection. These showed that through the use of different sizes and sites of corneal transplants, the relative lack of MHC class II positive dendritic cells and their uneven distribution in the cornea can explain the multifactorial character of corneal graft rejection. Thus, the corneal graft has the character of a 'naturally' APC-reduced transplant. The reduced importance of $\mathrm{MHC}$ and the greater importance of non-MHC in rat corneal graft rejection has been previously reported. $^{22}$ The class II MHC positive dendritic cells in the cornea are largely found at its periphery. The experiment with an eccentric corneal graft showed that a critical factor influencing corneal graft rejection is the presence and the high density of such dendritic cells in the graft (donor APCs). Thus, removal or inactivation of donor APCs could be effectively used to prevent corneal graft rejection by interrupting the immunological induction of the allograft rejection reaction.

$3 \mathbf{m m}$ rejecting corneal grafts (DA to $A O)$

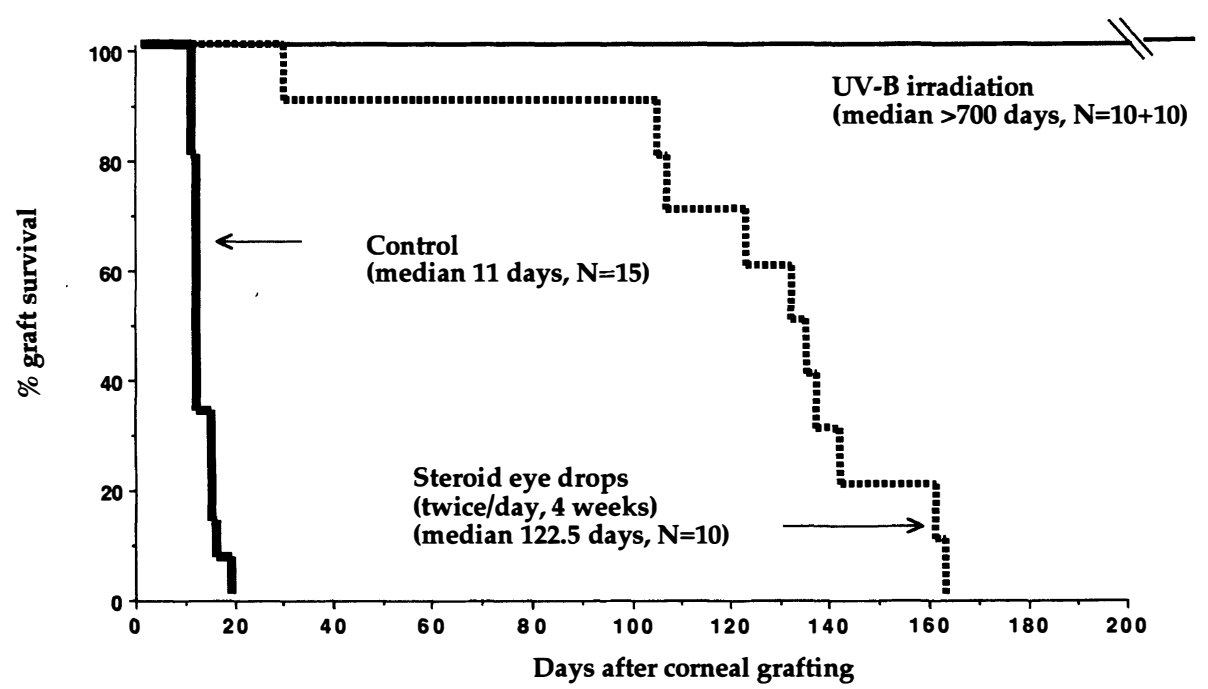

Fig. 8. Influence of $U V-B$ irradiation on corneal graft survival 
This has been done using pretreatment with UV-B irradiation, resulting in the reduction of allograft rejection. This observation could have major implications for the clinical practice of corneal transplantation.

Work from the author's laboratory was supported by grants from the Wellcome Trust (UK) and the Japanese Education Ministry. I should like to thank Mr Peter G. Watson, Dr David J. G. White, Dr Hugh ff. S. Davies, Dr Naoshi Kamada, Professor Sir Roy Calne and Professor Satoshi Ishikawa for their advice and encouragement in my work on rat corneal transplantation.

Key words: Antigen presenting cells, Corneal transplantation, MHC, Rats.

\section{REFERENCES}

1. Medawar PB. The behaviour and fate of skin autografts and skin homografts in rabbits. J Anat 1944;78:176-99.

2. Medawar PB. Immunity to homologous grafted skin. I. The suppression of cell division in grafts transplanted to immunised animals. Br J Exp Pathol 1946;27:9-14.

3. Medawar PB. Immunity to homologous grafted skin. III. The fate of skin homografts transplanted to the brain, to subcutaneous tissue, and to the anterior chamber of the eye. Br J Exp Pathol 1948;29:58-69.

4. Maumenee AE. The influence of donor-recipient sensitisation on corneal grafts. Am J Ophthalmol 1951;34:142-52.

5. Maumenee AE. The immune concept: its relation to corneal homotransplantation. Ann NY Acad Sci 1955;59:453-61.

6. Maumenee AE. Clinical aspects of corneal homograft reaction. Invest Ophthalmol 1962;1:244.

7. Günther E, Stark O. The major histocompatibility system of the rat (Ag-B or $\mathrm{H}-1$ system). In: Gotze DO, editor. The major histocompatibility system of man and animals. Berlin: Springer-Verlag, 1977:267.

8. Medawar PB. A second study of the behaviour and fate of skin homografts in rabbits. J Anat 1945;79:157.

9. Billingham RE, Boswell T. Studies in the problem of corneal homografts. Proc R Soc Lond 1953;141: 392-406.

10. Woodruff MFA. The transplantation of tissues and organs. Springfield, Illinois: CC Thomas, 1960.

11. Billingham RE, Silvers WK. Inbred animals and tissue transplantation immunity. Transplant Bull 1959;6:399.

12. Silverstein AM, Khodadoust AA. Transplantation immunology of the cornea. In: Knight J, Porter R. Corneal graft failure. Ciba Foundation Symposium 15. Amsterdam: Elsevier/North-Holland, 1973:105.

13. Khodadoust AA. Penetrating keratoplasty in the rabbit. Am J Ophthalmol 1968;66:899-905.

14. Williams KA, Coster DJ. Penetrating corneal transplantation in the inbred rat. Invest Ophthalmol Vis Sci 1985;36:23-30.

15. Casey TA, Meyer DJ. Corneal grafting: principle and practice. 1st ed. Philadelphia: WB Saunders, 1984.

16. Treseler PA, Sanfilippo F. The expression of major histocompatibility complex and leukocyte antigens by cells in the rat cornea. Transplantation 1986;41:229-34.

17. Katami M. PhD thesis, University of Cambridge, 1990.

18. Katami M, Madden PW, White DJG, Watson PG, Kamada N. The extent of immunological privilege of orthotopic corneal grafts in the inbred rat. Transplantation 1989;48:371-6.
19. Kamada N. PhD thesis, University of Cambridge, 1992.

20. Billingham RE, Brent L, Medawar PB. 'Actively acquired' tolerance of foreign cells. Nature 1953;172:603.

21. Calne RY, Sells RA, Pena JR, Davis DR, Millard PR, Herbertson $\mathrm{BM}$, et al. Induction of immunological tolerance by porcine liver allografts. Nature 1968;223:472-6.

22. Kamada N, Brons G, Davies HffS. Fully allogeneic liver grafting in rats induces a state of systemic nonreactivity to donor transplantation antigens. Transplantation 1980;29:429-31.

23. Lafferty KJ, Bootes A, Dart G, Talmage DW. Effect of organ culture on the survival of thyroid allografts in mice. Transplantation 1976;22:174.

24. Lacy PE, Davie JM, Finke EH. Prolongation of islet allograft survival following in vitro culture $\left(24^{\circ} \mathrm{C}\right)$ and a single injection of ALS. Science 1979;204:312-3.

25. Woehrle M, Beyer K, Bretzel RG, Federlin K. Preservation of islet allograft rejection in experimenta diabetes of the rat without immunosuppression of the host. Transplant Proc 1989;21:2705-6.

26. Lechler RI, Batchelor JR. Restoration of immunogenicity to passenger cell-depleted kidney allografts by the addition of donor strain dendritic cells. J Exp Med 1982;155:31-41.

27. Hardy MA, Lau HT, Reemsta K. Prolongation of rat islet allografts with the use of ultraviolet irradiation without immunosuppression. Transplant Proc 1984; $16: 865-9$.

28. Stepkowski S, Goto S, Reynolds K, Ito T, Kahan BD. Induction of unresponsiveness after local low-dose cyclosporine administration. Transplant Proc 1989; 21:1120-2.

29. Ruers TJM, Burman WA, van der Linden CJ. The relative importance of local versus systemic immune response in allograft rejection. Transplant Proc 1989; 21:149-50.

30. Kobayashi C, Kanai A, Nakajima A, Okumura K. Suppression of corneal graft rejection in rabbits by a new immunosuppressive agent, FK-506. Transplant Proc 1989;21:3156-8.

31. Burnet FM, Fenner F. The production of antibodies. 2nd ed. Melbourne: Macmillan, 1949.

32. Prowse SJ, Lafferty KJ. Organ transplantation and replacement. The normal immune response. Philadelphia: JB Lippincott, 1988:37.

33. Katami M. Corneal transplantation: immunologically privileged status. Eye 1991;5:528-48.

34. Matis LA, Glimcher LH, Paul WE, Schwartz RH. Magnitude of response of histocompatibility-restricted T-cell clones is a function of the product of the concentrations of antigen and Ia molecules. Proc Natl Acad Sci USA 1983;80:6019-23.

35. Ray-Keil L, Chandler J. Reduction in the incidence of rejection of heterotopic murine corneal transplants by pretreatment with ultraviolet radiation. Transplantation 1986;42:403-6.

36. Katami M, White DJG, Watson PG. Site-specific immunosuppression for corneal graft survival in the rat. Transplant Proc 1992;24:1406-8.

37. Lafferty KJ, Prowse SJ, Siomenovic CJ, Warren HS. Immunobiology of tissue transplantation: a return to the passenger leukocyte concept. Annu Rev Immunol 1983;1:143-73.

38. Snell GD. The homograft reaction. Annu Rev Microbiol 1957;11:439-58. 